\title{
Refractory element and Ti isotope constraints on parent material variability and elemental mobility in the Critical Zone.
}

\author{
LOUIS A DERRY ${ }^{1}$, KATHERINE E GRANT ${ }^{2}$, ZHENGBIN \\ DENG $^{3}$ AND FRÉDÉRIC MOYNIER ${ }^{4}$ \\ ${ }^{1}$ Institut de Physique du Globe de Paris \\ ${ }^{2}$ Lawrence Livermore National Laboratory \\ ${ }^{3}$ University of Copenhagen \\ ${ }^{4}$ Université de Paris, Institut de physique du globe de Paris \\ Presenting Author: derry@cornell.edu
}

Mass transfer in the Critical Zone is commonly estimated by calculating enrichment or depletion relative to a presumed "immobile" index element. It is important both to establish how immobile a proposed index element may actually be, and to constrain its variability in the parent material. Uncertainties in index element values or unrecognized mobile behavior can drive large uncertainties in calculated mass transfer coefficients. In volcanic landscapes, mixing of different compositions during a protracted and variable eruptive sequence can induce complex parent material compositions. Late stage eruptive activity on Kohala volcano (Hawai'i) evolves from tholeitic basalt to intermediate alkalic compositions with strongly varying refractory element chemistry following the onset of oxide fractionation [1]. We use Ti-Nb-Ta systematics along a soil transect to identify parent material variability and fractionation trends. Analysis of 93 Kohala regolith samples across wide variation in weathering intensity and substrate age yields constant $\mathrm{Nb} / \mathrm{Ta}=17.0 \pm 0.3$, very similar to magmatic values. $\mathrm{Nb} / \mathrm{Ta}$ appears robust in the weathering environment. $\mathrm{Ti} / \mathrm{Nb}$ in the Kohala regolith varies as expected for magmatic fractionation and is always within the range of fresh substrate. This is supported by regolith $\delta^{49} \mathrm{Ti}$ data that increase by $>0.6 \%$ with decreasing $\mathrm{TiO}_{2} / \mathrm{Nb}(0.13 \rightarrow 0.011) . \delta^{49} \mathrm{Ti}$ data in the weathered materials appear to preserve magmatic differentiation trends associated with the development of oxide saturation[1]. While $\mathrm{Ti}, \mathrm{Nb}$ and $\mathrm{Ta}$ show variations consistent with at most minor redistribution by weathering, $\mathrm{Zr}$, Hf and Th show mobility. $\mathrm{Zr} / \mathrm{Nb}$ declines with decreasing soil $\mathrm{pH}$ to values well outside the magmatic range. Consistent trends in $\mathrm{Ti}-\mathrm{Nb}-\delta^{49} \mathrm{Ti}$ permit robust estimates of parent material major element compositions despite variable magmatic inputs and high and variable weathering intensity.

[1] Spengler \& Garcia (1988) Geochemistry of Hawi lavas, Kohala volcano, Hawaii. Cont. Min. Pet. 99, 90-104.

[2] Deng, Chaussidon, Savage, Robert, Pik, \& Moynier (2019) Titanium isotopes as a tracer for the plume or island arc affinity of felsic rocks, PNAS 116, 1132-1135. 